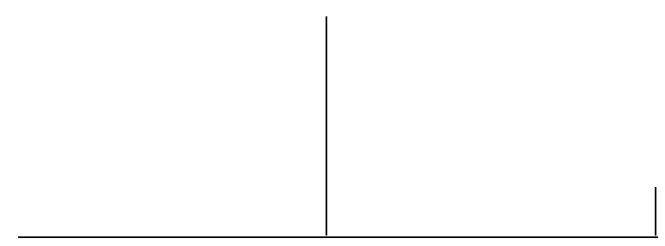

Rev. Latinoam. Psicopat. Fund., São Paulo, v. 14, n. 4, p. 721-727, dezembro 2011

\title{
Juliano Moreira e a (sua) história da assistência aos alienados no Brasil
}

Ana Maria Galdini Raimundo Oda

Apresenta o texto de Juliano Moreira, que em 1905 publicou uma história da assistência aos doentes mentais no Brasil, onde relata a criação do Hospício Pedro II (o primeiro do país), descreve a assistência na capital federal e em vários estados brasileiros e comenta a primeira lei federal relativa aos alienados, publicada em 1903. Este é um documento histórico importante, escrito por um dos principais protagonistas do projeto de modernização da psiquiatria nacional, em um momento-chave para sua consolidação institucional $e$ reconhecimento científico.

Palavras-chave: Hospício Nacional de Alienados - Brasil, Juliano Moreira, história da psiquiatria, legislação psiquiátrica - história 
O médico baiano Juliano Moreira (1873-1933) acumulou em quatro décadas de atuação profissional uma produção científica extensa e variada (sua bibliografia pode ser consultada em AMJRJ, 1933; Passos, 1975; Carvalhal e Delgado, 2000). Na fase inicial de sua carreira, ainda na Bahia, pesquisou sistematicamente afecções dermatológicas e infecciosas, tais como sífilis, lepra, ainhum e leishmaniose cutâneo-mucosa, sendo que esses trabalhos resultaram em contribuições científicas originais (Jacobina e Gelman, 2008). Durante o longo período (1903-1930) em que foi diretor do Hospício Nacional de Alienados do Rio de Janeiro, progressivamente concentrou suas publicações na área neuropsiquiátrica, em campos vários como psicopatologia, psiquiatria clínica, psiquiatria comparada, nosografia e modelos assistenciais.

Além disso, Moreira escreveu resenhas biográficas ou necrológios de ilustres contemporâneos (Pasteur, Magnan, Virchow, Silva Lima, Kraepelin, entre outros) e um estudo histórico sobre os médicos holandeses Willem Pies (Piso) e George Marcgrave, apresentado em sua posse como sócio do Instituto Histórico e Geográfico Brasileiro, em outubro de 1917 (IHGB, 1918).

Outro ensaio de cunho histórico é 'Notícia sobre a evolução da assistência a alienados no Brasil', impresso em março de 1905 junto ao relatório anual do diretor interino do Hospício Nacional de Alienados, Afrânio Peixoto, dirigido ao Ministro da Justiça e Negócios Interiores, J. J. Seabra (Moreira, 1905a). O mesmo texto aparece no primeiro número dos Arquivos Brasileiros de Psiquiatria, Neurologia e Ciências Afins, em abril de 1905 (Moreira, 1905b), que reeditamos aqui.

Nele, Moreira parte do período colonial e relata com detalhes o processo que culminou na criação do primeiro hospício de 
HISTÓRIA DA

PSIQUIATRIA

alienados do país, o Hospício Pedro II (fundado em 1841, inaugurado em 1852, renomeado Hospício Nacional em 1890), descrevendo sua história até 1904. Compila as informações, algumas bem escassas, que pôde obter sobre a história da assistência em vários estados brasileiros: São Paulo, Pernambuco, Bahia, Rio Grande do Sul, Pará, Amazonas, Maranhão, Ceará, Paraíba, Alagoas, Rio de Janeiro, Minas Gerais, Paraná, Goiás, Piauí, Mato Grosso. Também traça as origens e transcreve a primeira lei federal relativa aos alienados (o decreto 1.132, de 22 de dezembro de 1903) e expõe as reformas em andamento nos serviços (Hospício e colônias) da Assistência a Alienados do Distrito Federal, dirigidas por ele.

Vê-se que este é um grande esforço de pesquisa e síntese do diretor do Hospício Nacional, fruto de seu interesse pessoal pela história da psiquiatria e da medicina. Mas este não é um mero exercício de erudição voltado ao passado. A história narrada por Juliano Moreira está fortemente ligada ao (seu) presente, pois tem também a função de defender certa concepção modernizadora da ciência e da assistência psiquiátricas, em que têm importância fundamental a reorganização da assistência nos moldes propostos pelo decreto de dezembro de 1903 e legislação conexa (como o decreto de $1^{\circ}$ de fevereiro de 1904 , o Regulamento da Assistência a Alienados no Distrito Federal).

Neste sentido, o autor se coloca como parte atuante de um processo histórico em curso, quando estabelece os quatro marcos históricos que julgava capitais para a psiquiatria nacional: a fundação do Hospício Pedro II (1841); a criação do ensino de psiquiatria no Brasil (1882); a volta do Hospício Nacional à administração do Estado (1890) e a promulgação da lei federal de assistência a alienados (1903). Quanto a este último marco, Moreira deixa claro o seu empenho político e seus esforços junto ao governo federal para a aprovação da lei.

Recorde-se que Moreira assumiu o Hospício em um momento de crise, como ele menciona de passagem, logo depois que denúncias de graves irregularidades na assistência levaram à instalação de uma comissão de inquérito pelo Ministério da Justiça (órgão a que se subordinava o estabelecimento) em fins de 1902, e à demissão do então diretor Antonio Dias Barros. Como novo diretor do Hospício Nacional, ele diz que seu projeto ideal seria "obter do poder legislativo verba suficiente para a construção de um novo asilo-colônia, onde fossem atendidas todas as exigências da psiquiatria moderna". Porém, as dificuldades financeiras nacionais o levam a solicitar verbas apenas para "as mais inadiáveis reformas no Hospício". Assim, tem destaque a descrição das reformas físicas e das melhorias na assistência do Hospício, logo no início de sua gestão.

Vale ainda observar a "suposta digressão" no início do artigo, destinada, segundo o autor, a mostrar que "à má natureza dos elementos formadores de nossa nacionalidade deve-se a nossa vasta degenerescência física, moral e social que injustamente se tem ligado ao único fato da mestiçagem". Aqui, Moreira está se 


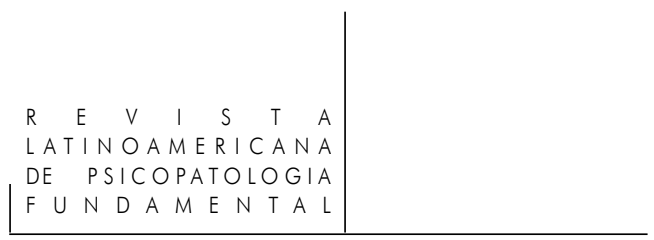

posicionando em um debate que envolvia os intelectuais brasileiros, na ocasião: as relações entre a composição racial do país e as perspectivas do Brasil firmar-se como nação moderna. Ele defendia a tese de que condição racial não protegeria ou predisporia a formas específicas de insanidade mental e que a mistura de raças não produziria sujeitos mais propensos à degenerescência mental e à loucura, e que as enfermidades mentais eram essencialmente as mesmas nas diversas latitudes, sendo que o progresso traria consigo o aumento da alienação mental. Esse era um tema caro a Moreira, que o retomaria em vários estudos (ver Oda e Piccinini, 2005).

Finalmente, outro aspecto a considerar é a (re)publicação no estreante $A r$ quivos Brasileiros de Psiquiatria. Primeiro periódico nacional especializado em psiquiatria, fundado por Juliano Moreira e Afrânio Peixoto e impresso na tipografia do Hospício Nacional, a revista se configurava como um meio de articulação científica e política no processo de consolidação do incipiente campo psiquiátrico nacional, e a publicação do texto de Moreira esboça ali uma espécie de "história oficial" da nascente especialidade.

Em síntese, oferecemos ao leitor um documento histórico significativo, escrito por um dos principais protagonistas do projeto de modernização da psiquiatria nacional nos inícios do século XX, momento em que o recente Estado republicano buscava reformar e modernizar as instituições e a nação.

\section{Referências}

Arquivos do Manicômio Judiciário do Rio de Janeiro (AMJRJ). Professor Juliano Moreira. Arquivos do Manicômio Judiciário do Rio de Janeiro, Rio de Janeiro, v. 4, n. 1-2, p. 3-20, 1933.

Carvalhal, L.A.; Delgado, P.G. Levantamento de fontes primárias e secundárias relativas a Juliano Moreira (1873-1933). In: Amarante, P. (org.). A loucura da (na) história. Rio de Janeiro: LAPS/ ENSP/ FIOCRUZ, 2000. p. 421-433.

Instituto Histórico e Geográfico Brasileiro (IHGB). Ata da reunião de 16 de outubro de 1917 [discurso de posse do sócio efetivo Juliano Moreira]. Revista do Instituto Histórico e Geográfico Brasileiro. Rio de Janeiro, tomo 82, p. 791-807, 1918. Disponível em: 〈http://www.ihgb.org.br/rihgb.php>. Acesso em: 01 out. 2011.

Jacobina, R.R.; Gelman, E.A. Juliano Moreira e a Gazeta Médica da Bahia. História, Ciências, Saúde - Manguinhos. Rio de Janeiro, v. 15, n. 4, p. 1077-1097, dez. 2008.

Disponível em: <http://www.scielo.br/scielo.php?script=sci_arttext\&pid=S010459702008000400011\&lng=pt\&nrm=iso >. Acesso em: 01 out. 2011. 
HISTÓRIA DA

PSIQUIATRIA

Moreira, J. Notícia sobre a evolução da assistência a alienados no Brasil, pelo Dr. Juliano Moreira, Diretor do Hospício Nacional de Alienados. 34p. In: Brasil. Ministério da Justiça. Relatório dos anos de 1904 e 1905, apresentado ao presidente da República dos Estados Unidos do Brasil pelo Dr. J. J. Seabra, em março de 1905. Volume II, Diretoria do Interior, segunda parte, anexo E. Rio de Janeiro: Imprensa Nacional, 1905a. Disponível em: 〈http://brazil.crl.edu/bsd/bsd/u1889/000888.html>. Acesso em: 01 out. 2011.

. Notícia sobre a evolução da assistência a alienados no Brasil. Arquivos Brasileiros de Psiquiatria, Neurologia e Ciências Afins, Rio de Janeiro, v. 1, n. 1, p. 52-98, $1905 \mathrm{~b}$.

. Psiquiatria. In: Academia Nacional de Medicina. Em comemoração ao centenário do ensino médico. Rio de Janeiro: Tipografia do Jornal do Commercio, 1908. p. 432-448.

OdA, A.M.G.R.; PiccininI, W. Dos males que acompanham o progresso do Brasil: a psicopatologia comparada de Juliano Moreira e colaboradores. Revista Latinoamericana de Psicopatologia Fundamental, v. 8, n. 4, p. 788-793, dez. 2005. Disponível em: <http://www.fundamentalpsychopathology.org/art/v08_04/historia.pdf>. Acesso em: 01 out. 2011.

Passos, A. Juliano Moreira (vida e obra). Rio de Janeiro: Livraria São José, 1975.

Peixoto, A. Relatório apresentado ao Exmo. Sr. Dr. J. J. Seabra, Ministro da Justiça e Negócios Interiores, pelo Dr. Afranio Peixoto, diretor interino do Hospício Nacional de Alienados (1904-1905). 73 p. In: Brasil. Ministério da Justiça. Relatório dos anos de 1904 e 1905, apresentado ao presidente da República dos Estados Unidos do Brasil pelo Dr. J. J. Seabra, em março de 1905. Volume II, Diretoria do Interior, segunda parte, anexo E. Rio de Janeiro: Imprensa Nacional, 1905. Disponível em: <http://brazil.crl.edu/bsd/bsd/u1889/000002.html〉. Acesso em: 01 out. 2011.

Resumos

(Juliano Moreira and (his) history of aid to the insane in Brazil)

This article comments on a text by Juliano Moreira, who, in 1905, published a history of aid to the mentally ill in Brazil, where he tells of the founding of the Pedro II Asylum (the first in the country), describes the aid provided in Rio de Janeiro, then capital of Brazil, and in several Brazilian states, and comments on the first Federal Law for the insane, enacted in 1903. This is an important historical document written by one of the most outstanding protagonists of the project for modernizing Brazilian psychiatry 
during a period that was essential for its institutional consolidation and scientific recognition.

Keywords: National Asylum for the Insane - Brazil, Juliano Moreira, history of psychiatry, psychiatric legislation - history

(Juliano Moreira et l'histoire (son histoire) des services pour malades mentaux au Brésil)

Cet article propose un commentaire sur le texte de Juliano Moreira qui publie en 1905 l'histoire des services pour les malades mentaux au Brésil et qui raconte la création de l'Hospice Pedro II (le premier au Brésil). Il décrit d'ailleurs les services de la capitale fédérale et de plusieurs états du Brésil et commente la première Loi fédérale sur les malades mentaux publiée en 1903. Il s'agit d'un document historique important qui a été rédigé par l'un des principaux protagonistes du projet de modernisation de la psychiatrie à l'échelle nationale lors d'un moment clé pour sa consolidation institutionnelle et sa reconnaissance scientifique.

Mots clés: Hospice National des Aliénés - Brésil, Juliano Moreira, Histoire de la Psychiatrie, Législation Psychiatrique - Histoire

(Juliano Moreira y (su) historia de la asistencia a los alienados en Brasil)

Se presenta el texto de Juliano Moreira quien en 1905 publicó una historia de la asistencia a los enfermos mentales en Brasil. En el texto se relata la creación del Hospital Psiquiátrico Pedro II ( el primero en el país). Se describe la asistencia que se daba en la Capital Federal (Caberia colocar: la ciudad de Rio de Janeiro?) y en varios estados brasileños así como se comenta la primera ley federal que se refiere a los locos publicada en 1903. Este es un documento histórico importanto, escrito por uno de los principales protagonistas del proyecto de modernización de la psiquiatria nacional, en un momento clave para su consolidación institucional y reconocimiento científico.

Palabras claves: Hospicio Nacional de locos - Brasil, Juliano Moreira, historia de la psiquiatria, legislación psiquiátrica - historia

Citação/Citation: OdA, A.M.G.R. Juliano Moreira e a (sua) história da assistência aos alienados no Brasil. Revista Latinoamericana de Psicopatologia Fundamental, São Paulo, v. 14, n. 4, p. 721-727, dez.2011.

Editor do artigo/Editor: Prof. Dr. Paulo Dalgalarrondo; Profa. Dra. Ana Maria Galdini Raimundo Oda.

Rev. Latinoam. Psicopat. Fund., São Paulo, v. 14, n. 4, p. 721-727, dezembro 2011 
Recebido/Received: 6.11.2011 / 11.6.2011 Aceito/Accepted: 20.11.2011 / 11.20.2011

Copyright: () 2009 Associação Universitária de Pesquisa em Psicopatologia Fundamental/ University Association for Research in Fundamental Psychopathology. Este é um artigo de livre acesso, que permite uso irrestrito, distribuição e reprodução em qualquer meio, desde que o autor e a fonte sejam citados/This is an open-access article, which permits unrestricted use, distribution, and reproduction in any medium, provided the original author and source are credited.

Financiamento/Funding: A autora declara não ter sido financiada ou apoiada/The author has no support or funding to report.

Conflito de interesses/Conflict of interest: A autora declara que não há conflito de interesses/The author declares that has no conflict of interest.

\section{Ana Maria Galdini Raimundo Oda}

Médica psiquiatra; doutora em Ciências Médicas (2003) pela Universidade Estadual de Campinas (Campinas, SP, Brasil); editora associada da Revista Latinoamericana de Psicopatologia Fundamental (seção História da Psiquiatria); secretária do Departamento de História da Psiquiatria da Associação Brasileira de Psiquiatria; professora adjunta do Departamento de Medicina do Centro de Ciências Biológicas e da Saúde da Universidade Federal de São Carlos (São Carlos, SP, Brasil).

Universidade Federal de São Carlos

CCBS - Departamento de Medicina

Rodovia Washington Luis, Km 235

13565-905 São Carlos, SP, Brasil

e-mail: anaoda@ufscar.br 